\title{
The Power of the Symposium: Impacts from Students' Perspectives
}

\author{
Diana Vanek; Nancy Marra; Carolyn Hester; Desirae Ware; Andrij Holian; Tony Ward \\ The University of Montana, Center for Environmental Health Sciences, Missoula \\ Randy Knuth \\ Knuth Research Inc. \\ Earle Adams \\ The University of Montana, Department of Chemistry, Missoula
}

\begin{abstract}
The Air Toxics under the Big Sky program developed at the University of Montana is a regional outreach and education initiative that offers a yearlong exploration of air quality and its relation to respiratory health. The program was designed to connect university staff and resources with rural schools enabling students to learn and apply science process skills through self-designed research projects conducted within their communities. As part of the program, students develop and conduct independent projects, then share their findings at the conclusion of the school year in some type of interactive capstone experience, the most prominent being a high school symposium held at The University of Montana campus. Student feedback collected through a carefully controlled evaluation program suggest that the annual symposium as the culminating event is a critical component of the Air Toxics Under the Big Sky program, and a valuable learning experience as many of the students go on to post-secondary education.
\end{abstract}

Key words: $\mathrm{PM}_{2.5}$; Inquiry-based / discovery learning; symposium; environmental chemistry.

The Air Toxics Under the Big Sky program was designed to bring student-based scientific inquiry into the classroom, give students real-world experience on problems relevant to their communities, and encourage young people to seek further education and careers in environmental and biomedical sciences (Jones et al., 2007; Adams et al., 2008). The program began in 2003 when one student expressed an interest to his high school chemistry teacher in studying air pollution. With support from researchers from the University of Montana (UM), a year-long science project was implemented to study indoor air quality in the homes of 16 junior/senior level classmates. Since then, the program has greatly expanded throughout Montana, Idaho, and Alaska. As of the 2010 school year, this student-led research program has involved over 1200 students from 18 schools (including high school and junior high grade levels and an undergraduate liberal arts chemistry class at UM). Apart from schools in Missoula and Butte, Montana, the majority of schools represented are located in rural and remote areas, and include two Native tribal colleges. Table 1 presents the participating schools from the 2010/2011 school year.

The main components of the Air Toxics Under the Big Sky Program have been presented and discussed in previous publications (Adams et al., 2009; Ward et al., 2008). Briefly, prior to the start of the school year, a workshop is held at UM where new incoming teachers are introduced to the program. Teachers are then provided with a binder containing multiple environmental health lesson plans to support an inquiry-based teaching approach (NSF, 2000) as a part of their chemistry, biology, or research problems classes. A UM researcher then visits classrooms early in the school year to provide an overview of air pollution issues in the western US, and how they link with rates of asthma and other chronic diseases.

Following the in-class presentations, the classroom is provided with an air sampler, along with comprehensive training on how to use the instrument. The students then use the air sampler to collect data in support of their hypothesis-driven research projects focused on a realworld air pollution issue of concern within their homes and communities. Specifically, students measure $\mathbf{P M}_{2.5}$ (microscopic airborne particles), a type of air pollution that has been shown to result in adverse health effects upon prolonged exposure (Krewski et al., 2009; Samet, Dominicic, Curriero, Coursac, \& Zeger, 2000). $\mathrm{PM}_{2.5}$ is also the major air pollutant in many areas of Montana, Idaho, and Alaska (Ward \& Lange, 2010). 
Table 1

Schools Participating in the Air Toxics Under the Big Sky Program during the 2010/2011 School Year

\begin{tabular}{|c|c|c|c|c|}
\hline School & $\begin{array}{l}\text { Grade } \\
\text { Levels }\end{array}$ & $\begin{array}{l}\text { Community } \\
\text { Population }\end{array}$ & $\begin{array}{c}\text { School } \\
\text { Enrollment }\end{array}$ & $\begin{array}{c}\text { Number of Students } \\
\text { in Participating } \\
\text { Class }\end{array}$ \\
\hline Big Sky High School, Missoula, MT & $9-12$ & 64,081 & 1,349 & 45 \\
\hline Hellgate High School, Missoula, MT & $9-12$ & 64,081 & 1,272 & 35 \\
\hline Sentinel High School, Missoula, MT & $9-12$ & 64,081 & 1,105 & 1 \\
\hline Corvallis High School, Corvallis, MT & $9-12$ & 491 & 475 & 65 \\
\hline Libby High School, Libby, MT & $9-12$ & 2,880 & 532 & 15 \\
\hline Whitefish High School Whitefish, MT & $9-12$ & 5,873 & 725 & 45 \\
\hline Butte Central High School Butte, MT & $9-12$ & 32,268 & 150 & 15 \\
\hline Kamiah High School ID Nez Perce Reservation & $9-12$ & 1,130 & 171 & 13 \\
\hline Lapwai High School, ID Nez Perce Reservation & $9-12$ & 1,129 & 146 & 42 \\
\hline Hoonah Jr/Sr High School, AK & $7-12$ & 764 & 92 & 9 \\
\hline Palmer High School Palmer, AK & $9-12$ & 5,532 & 917 & 25 \\
\hline Glennallen Jr/Sr High School, AK & $7-12$ & 473 & 183 & 24 \\
\hline Kenny Lake School,AK & $\mathrm{K}-12$ & 412 & 122 & 8 \\
\hline $\begin{array}{l}\text { Paul T. Albert Memorial School, } \\
\text { Tununak, AK }\end{array}$ & $\mathrm{K}-12$ & 330 & 109 & 21 \\
\hline $\begin{array}{l}\text { Kuinerrarmiut Elitnaurviat School, } \\
\text { Quinhagak, AK }\end{array}$ & $\mathrm{K}-12$ & 680 & 156 & 18 \\
\hline $\begin{array}{l}\text { Z. John Williams Memorial School, } \\
\text { Napaskiak, AK }\end{array}$ & $\mathrm{K}-12$ & 428 & 125 & 16 \\
\hline Kobuk School, AK & $\mathrm{K}-8$ & 122 & 42 & 5 \\
\hline Nuiqsut Trapper School, AK & $\mathrm{K}-12$ & 424 & 143 & 12 \\
\hline
\end{tabular}

Finally, students devise ways to share their findings with others via posters, community reports, or participation in the annual Air Toxics Under the Big Sky Symposium on the UM campus held at the conclusion of the school year. Throughout the program, students are encouraged to conduct their experiments and present the findings of their student-led, collaborative research projects in a manner consistent with the conventions of scientific communication (Marcum-Dietrich, 2010; Romanello, 2005). The program also reinforces the importance of developing science process skills such as careful experimental design, data synthesis and interpretation, and drawing accurate conclusions about the results of experiments - all important skills required for students to succeed in science at the college level (ACT, 2009).

The effectiveness of the Air Toxics Under the Big Sky program has been confirmed through rigorous assessment by an external (independent) evaluator. Through these evaluations, it has become clear that one of the most important components of the Air Toxics Under the Big Sky program is the symposium held at the conclusion of each school year. In this manuscript, we present the findings of independent evaluations carried out over a three-year period that demonstrate the importance of the culminating event in enhancing learning outcomes and community engagement. We also describe how the current symposium has evolved through the years in an effort to accommodate the increased numbers of participating schools in widely dispersed rural communities.

As part of the Air Toxics Under the Big Sky program, we encourage students to disseminate their research results. In the past, this has been done through a variety of ways, including: science fair participation, newspaper article submissions, production of informational brochures, sponsorship of open house nights at participating schools, environmental health fair involvement, and participation in the annual symposium held on the UM campus. Many successes (for example, medals, ribbons, publications, media recognition, placement at regional and national events) have been realized for our students since the program began in 2003.

\section{The Air Toxics Under the Big Sky Symposium}

The majority of the schools participating in the program each year (in Montana and Idaho) opt to bring their classes to the annual UM symposium held in May of each year. The first symposium (2004) welcomed 86 students, while the latest one (2010) involved more than 200 students from multiple regional high schools. In 
addition to students, this event brings together teachers, community members, public officials, UM faculty, and researchers in one of the largest lecture halls on the UM campus.

At the annual symposium, presenters have two options for sharing their research findings: via oral presentations using PowerPoint, or via posters. Both the oral presentations and poster sessions have separate judging panels that determine awards for best oral and poster presentations, respectively. The five-member judging panel for the presentations is composed of local celebrities, including regional television personalities, UM coaches, and others. The poster session judging panel is composed of three to five volunteers from UM.

The symposium typically lasts from 9:00 AM to 2:00 PM; therefore, it is difficult to accommodate presentations from each group from every participating school. As there is a limited number of slots, the teachers are informed prior to the event how many presentations they are allotted for their respective schools. Leading up to the event, teachers choose those projects that will be presented by the teams and those and that will be disseminated through posters. It is the desired goal that all students have the opportunity to present their findings through one of these mechanisms. Our most recent symposium (May 2010) included 22 group presentations, and 25 poster posters.

Depending on class size and teacher preference, students are typically organized in teams ranging in size from two to five members (for both presentations and posters). The teams choosing the oral presentation route are afforded five minutes to present their findings, followed by one minute of question and answer time. In the interest of saving time and avoiding redundancy, it is recommended that students minimize details on background materials and instead concentrate on presenting the experimental design, results, and conclusions of their research. Student groups choosing the poster option have their work displayed for public viewing during the designated poster session. These students are encouraged to present background materials in addition to the experimental design, results, and conclusions of their research. At the conclusion of the symposium, the winners $\left(1^{\text {st }}, 2^{\text {nd }}\right.$, and $3^{\text {rd }}$ place for the presentations and poster sessions, respectively) are announced, and the teams are acknowledged in front of their peers.

\section{Evaluation Process}

As part of our National Institutes of Health Science Education Partnership Award funding, an independent evaluation was conducted on the Air Toxics Under the
Big Sky program. One of the evaluation goals was to gather student perceptions about the annual symposium. Data were collected through an end-of-symposium survey (paper) that took approximately 15 minutes to complete, and included six questions about the symposium experience. Over the 2006-07, 2007-08, and 2008-09 school years, a total of 448 student surveys from nine schools were collected. Most of the participating students were 17 years of age $(51 \%)$ and in the 11 th grade $(56 \%)$ at the time of their symposium presentations. Tenth and 12th-graders also participated, ages ranging from 15 to 19 years old. Overall, more females than males that submitted surveys (56\% and $44 \%$, respectively).

\section{Results}

The first survey question asked students to rate how well they thought their presentations went on a scale of 'really bad,' 'not so good,' about average,' good,' or 'excellent.' Nearly three-fourths indicated that their presentation went either good (53\%) or excellent (19\%). About $22 \%$ felt it was 'about average,' only $4 \%$ reported that it was 'not so good' and less than $2 \%$ circled 'really bad.' This trend was consistent for each of the three symposia.

An important purpose of making a presentation to a scientific community is to share findings and insights that result from inquiry. Therefore, students were asked to list the most important things that they hoped their audience would learn from their presentations. Nine categories emerged through a card sort procedure in which responses were grouped into piles containing similar concepts. After the procedure was completed, about a third of the responses fell into a category that was labeled "the causes of poor air quality." Another third of the responses dealt with two concepts: "the importance of having good quality air and how to improve it" and "specific information about air pollution and other dangerous chemicals." One out of ten students wanted the audience to learn about "the effects of poor air quality on health", while another $10 \%$ indicated that the objective was for the audience to learn about "general air quality issues, especially $\mathrm{PM}_{2.5}$.

Students were then asked to describe the most important things that they had learned as a result of working on their project and giving their symposium presentations. A card sort procedure was again used which generated nine response categories. The most frequently given response (nearly $30 \%$ ) dealt with students' increased "general awareness of air quality and particulate matter." About a fifth listed knowledge related to "conducting scientific research and participating in the research process." Less than one percent of respondents 
reported that they "learned nothing" from the project. Some students reported that they learned about "the effects of poor air quality on health and the environment" (12\%) or "the need to improve air quality and ways to do it" (12\%). Others gained knowledge or skills related to "planning and working on a project or presentation" (7\%), "improving presentation and public speaking skills" (4\%) or "working as a team" (3\%).

Presenting to a large audience of one's peers can be a daunting experience. After having participated an event of this magnitude for the first time it becomes clear to students what they could do in the future to improve their performance. On the survey we asked students a related question: "If you were to give your presentation again in the future, how would you make it better?" The category with the most responses (almost a third) focused on strengthening their research during the school year. In students' responses to questions from the judges it was common to hear them describe their desires to control for more variables or collect more data points. The second highest ranked item (14\% of responses) focused on including more information in their future presentations. That is, students reported that they would like their presentations to be more comprehensive. About $14 \%$ of students felt that practicing their presentation beforehand would have improved their presentations, while about $13 \%$ thought they could have done a better job of explaining and answering questions during their presentations. Almost $10 \%$ of students stated they would spend more time putting together their PowerPoint presentation.

A long-term goal of the Air Toxics Under the Big Sky program is to build the pipeline of students entering scientific careers. Thus, the survey asked students to describe what impact their experiences at the UM symposium would have on their lives. A primary impact listed by nearly a quarter of all students was that clean air is important, and that they now know about ways to improve it. In ranks two, three, and five, respectively, (38\% of all responses) the impacts listed dealt with increased knowledge about air pollution, improved public presentation skills, and an increased ability to conduct scientific research.

In addition to giving their own presentations, students also had the opportunity to observe presentations from other students and listen to and interact with UM staff and researchers. To get a sense of their perceived value of the day, students were asked to rate their overall experience at the symposium. An overwhelming percentage of students $(85 \%)$ rated their experience at the University of Montana symposium as either 'good' (59\%) or 'excellent' (26\%). More females gave a 'good' rating than did males $(61 \%$ versus $55 \%$, respectively), while the same proportion of males and females rated it as 'excellent' (26\%). Overall, only $13 \%$ of students indicated that their day was about average and only about $2 \%$ said that it was either 'not so good' or 'really bad.' These ratings were fairly consistent for each of the symposia for which data were available.

The survey also contained questions about the Air Toxics Under the Big Sky program in general. Responses to two of those questions are particularly important. Students were asked whether the program changed their interest in (1) science and (2) in pursuing a science career. Thirty-six percent of students, after having just given their presentations, reported that they were more interested in science as a content area, and $24 \%$ reported an increased interested in a science career. This is a notable, since a large number of these students were in elective science classes in which students may be expected to have high levels of science and science career interest. Any reported career interest increases by these students suggest that the Air Toxics Under the Big Sky program, with its culminating symposium, is a powerful way to have an impact on those who already have a high level of science interest.

\section{Discussion}

Instituting a capstone experience (such as a Symposium) as an integral part of student research projects provides a strong incentive for young researchers to hone their research methods as well as their communication skills. This culminating experience has been used successfully in other studies as well. For example, an inquiry project focusing on water quality involving high school teachers and students in Missouri had an annual science symposium, providing a forum for students to present and discuss their scientific results in front of peers, scientists and school administrators (Sarkar \& Frazier, 2008). At the conclusion of the projects, teachers noted improvements in students' performance in content and skills areas, as well as their overall attitude and enthusiasm. Two more inquiry projects involving $\mathrm{K}$ 12 students which focused on local environmental issues (Sedlacek, Young, Acharya, Botta, \& Burbacher, 2005) and indoor air quality (Hanes \& Sadler, 2005) also had students prepare posters and oral presentations for local community and school boards, as well as their peers. While there was a lack of formal assessment in these projects, both studies reported that the sharing of scientific results to others gave students experience in communicating their results in a concise and balanced way, and allowed students to make a connection to their communities through their research.

Survey data collected from student participants as part of this study are encouraging, and suggest that the 
symposium component of the Air Toxics Under the Big Sky program is a valuable student experience. The majority of students reported that their presentations went well and that they had a positive experience. They were able to articulate what they wanted their audience to learn: findings directly related to their research projects. And students were mindful about what they had learned as a result of giving their presentations: knowledge related to air pollution, scientific procedures, working on team projects, and giving public presentations. They were also very aware of what they needed to do to improve: conduct better research, be more comprehensive in their information, practice, and spend more time developing their presentations. Specifically students knew they would need to have more data, control for more variables, and spend more time and care in the data collection process.

\section{Alternative Culminating Events}

As the program has expanded, strategies for enhancing the culminating events have been developed based on the needs of individual teachers. Since many of the participating schools are located in rural areas dispersed throughout three states (Montana, Idaho, and Alaska), the program has devised a variety of alternative culminating events or capstone experiences from which to choose: science fairs, school assemblies, open houses, traveling poster shows, and virtual symposia using distance learning capabilities.

The virtual symposium option was piloted in May 2009 by using a videoconferencing technology interface to connect UM researchers with students from high schools in Hoonah and Wasilla, Alaska. This undertaking forged an additional connection within their respective communities. As the schools didn't have teleconferencing capabilities themselves, Wasilla students accessed a teleconferencing facility by traveling to the main Matanuska-Susitna Borough School District offices in nearby Palmer. In a cooperative arrangement with the US Department of Agriculture, Hoonah students were able to use technology housed in the nearby United States Forest Service building. These alternatives alleviated travel, budget and scheduling issues, which can be problematic for rural schools, particularly at the end of the academic year.
As the Air Toxics Under the Big Sky program expands into rural areas outside Montana, the challenge is to maintain the campus-community connection by leveraging interactive teleconferencing tools, community events, and media involvement so that students communicate their research projects and data to the widest possible audience. Traveling poster exhibits also have potential to extend the curriculum into communities served by the student investigations on local air quality issues.

\section{Conclusion}

In follow up meetings, teachers in the Air Toxics Under the Big Sky program have pointed out that the annual symposium is an important event for the students for several reasons: 1) It is the culmination after a year of activities (including student project design and hypothesis, data collection, analysis, and finally organization of an oral or poster presentation), 2) The process of going through the collection and analysis of experimental data and organizing the material in either an oral presentation or in a poster format to an audience of researchers, judges, and their own peers 'raises the bar' for student performance and expectations, and 3) Students from different high schools working on indoor air quality projects have a chance to share their results and problems encountered in the process of their research, as well as observations about their overall experiences from the year's work.

The symposium, whether conducted as a virtual competition through distance delivery methods or as an in-person live event on the UM campus, offers a valuable educational experience for rural science students. The focus on indoor air quality experiments conveys the relevance of air pollution in the context of everyday life. The findings from the students' projects are being used to educate others (parents, fellow students, teachers, and community members) on the importance of good air quality, and the steps they themselves can take to improve air quality within their homes, schools, and communities. A culminating event such as the UM Air Toxics Under the Big Sky symposium also provides many of the students with an invaluable learning experience of presenting their research findings to their peers - a skill they will need as they pursue their college educations.

\section{References}

ACT. (2009). Focusing on the essentials for college and career readiness: Policy implications of the ACT
National Curriculum survey results 2009. Retrieved from 
http://www.act.org/research/policymakers/pdf/NCS_ PolicySummary2009.pdf

Adams, E., Smith, G., Ward, T., Vanek, D., Marra, N., Jones, D., Henthorn, M., \& Striebel, J. (2008). Air toxics under the big sky: a real world investigation to engage high school science students. Journal of Chemical Education, 85(2), 221-224.

Adams, E., Ward, T., Vanek, D., Marra, N., Hester, C., \& Knuth, R. (2009). The big sky inside: Measuring rural indoor air quality and its impact on the community. The Science Teacher, 76(4), 40-45.

Hanes, J., \& Sadler, T.D. (2005). Inquiry in the community. The Science Teacher, 72(4), 42- 43.

Jones, D., Ward, T., Vanek, D., Marra, N., Noonan, C., Smith, G., and Adams, A. (2007). Air toxics under the big sky -- a high school science teaching tool. Science Education \& Civic Engagement: An International Journal, 1(2), 51-55.

Krewski, D., Jerrett, M., Burnett, R., Ma, R., Hughes, E., Shi, Y., et al. (2009). Extended follow-up and spatial analysis of the American Cancer Society study linking particulate air pollution and mortality. (Health Effects Institute Report \#140, 2009-06-03).

Retrieved May 4, 2011, from http://www.healtheffects.org/Pubs/RR140Krewski.pdf

Marcum-Dietrich, N. (2010). Talk like a scientist: using science symposiums in the classroom. The Science Teacher, 77(4), 45.
National Science Foundation. (2000). Foundations volume 2: Inquiry thoughts, views, and strategies for the $K$-5 classroom. Retrieved from http://www.nsf.gov/pubs/2000/nsf99148/lcd/ch_12.htm

Romanello, T. (2005). Collaborative competition? A great way to teach and motivate. The Physics Teacher, 43(2), 76-78.

Samet, J.M., Dominici, F., Curriero, F., Coursac, I., \& Zeger, S.L. (2000). Particulate air pollution and mortality: findings from 20 U.S. cities. New England Journal of Medicine, 343,1742-1757.

Sarkar, S., \& Frazier, R. (2008). Place-based investigations and authentic inquiry. The Science Teacher, 75(2), 29-33.

Sedlacek, N., Young, J.A., Acharya, C., Botta, D., \& Burbacher., M. (2005). Linking the classroom to the community. The Science Teacher, 72(4), 44-45.

Ward, T., Vanek, D., Marra, N., Holian, A., Adams, E., Jones, D., \& Knuth, R. (2008). The big sky model: A regional collaboration for participatory research on environmental health in the rural west. Journal of Higher Education Outreach and Engagement, 12(3), 103-115.

Ward, T., \& Lange T. (2010). The impact of wood smoke on ambient PM2.5 in northern Rocky Mountain valley communities. Environmental Pollution, 158(3), 723-72.

\section{Acknowledgments}

The authors wish to thank all the students who have participated in the Air Toxics Under the Big Sky Program, with our special gratitude toward the many dedicated teachers who have made its implementation so successful and rewarding. Funding for this project was provided by the Toyota USA Foundation and by a Science Education Partnership Award, Grant Number R25 RR020432, from the National Center for Research Resources, a component of the National Institutes of Health. The contents of this manuscript are solely the responsibility of the authors and do not necessarily represent the officials views of our funding sponsors.

\section{About the Authors}

Diana Vanek is the outreach coordinator for the UM Center for Environmental Health Sciences and serves as co-investigator on the SEPA project. Her role at the UM CEHS involves promoting meaningful collaborations between university-based scientists and communities to enhance the public's role in identifying biomedical research priorities with the goal of improving environmental public health.

Nancy Marra is the former CEHS education coordinator under the SEPA grant program. She has been involved in the field of education for 25 years in many different capacities and now serves as the director of field experiences for pre-service teachers at UM.

Carolyn Hester is a project manager at the Center for Environmental Health Sciences. Through her work, she focuses on educating teachers and students in the rural west about air quality issues and their link to human health. She also conducts air quality research, has a bachelor's degree in Environmental Toxicology, and was previously a High School science teacher. 
Desirae Ware is the Project Manager at the Center for Environmental Health Sciences. In this role, she works with schools in rural communities to build capacity for an educational project aiming to increase knowledge of air quality issues and the impact on human health. Desirae holds a bachelor's degree in Health and Human Performance and a Master of Public Health.

Andrij Holian is the director of the UM Center for Environmental Health Sciences within the Department of Biomedical and Pharmaceutical Sciences. He is the principle investigator on the Environmental Health Science Education for Rural Youth SEPA project. Dr. Holian received a Ph.D. in Chemistry from Montana State University.

Tony Ward is an Assistant Professor at The University of Montana's Center for Environmental Health Sciences (CEHS). In addition to conducting research on air quality and respiratory health, he also teaches in the University of Montana's School of Public and Community Health Sciences, and is an adjunct faculty with the University of Montana Department of Chemistry.

Randy Knuth is the External Evaluator and designs and implements program evaluations in collaboration with universities, corporations, and community not-for-profit organizations. As part of the 'Air Toxics' collaborative, he designs quantitative surveys and assessments will be identified and developed to provide objective analysis of the achievement of project outcomes.

Earle Adams is an Assistant Research Professor at The University of Montana, Department of Chemistry and Biochemistry. He teaches liberal arts chemistry in the Chemistry Department, laboratory manager of the Magnetic Resonance Facility, and K12 outreach coordinator in the department. 